\title{
Ecological implications of climate change will include surprises
}

\author{
STEPHEN H. SCHNEIDER \\ Department of Biological Sciences and Institute for International Studies, Stanford University, Stanford, CA \\ 94305-5020, USA
}

TERRY L. ROOT

School of Natural Resources \& Environment, University of Michigan, Ann Arbor, MI 48109-1115, USA

Received 30 September 1995; revised and accepted 23 April 1996

In addition to assessing the impacts of $\mathrm{CO}_{2}$ doubling on environment and society, more consideration is needed to estimate extreme events or 'surprises'. This is particularly important at the intersection of disciplines like climate and ecology because the potential for large discontinuities is high given all the possible climate/biota interactions. The vast disparities in scales encountered by those working in traditional ecology (typically $20 \mathrm{~m}$ ) and climatology (typically $200 \mathrm{~km}$ ) make diagnoses of such interactions difficult, but these can be addressed by an emerging research paradigm we call strategic cyclical scaling (SCS). The need to anticipate outlier events and assign them subjective probabilities suggests emphasis on interdisciplinary research associations. The desire to reduce societal vulnerability to such events suggests the need to build adaptive management and diverse economic activities into social organizations. The effectiveness of adaptation responses to anticipated climatic changes is complicated when consideration of transient changes, regional disturbances, large unforseeable natural fluctuations and surprises are considered. Slowing down the rate of disturbances and decreasing vulnerability are advocated as the most prudent responses to the prospect of human-induced climatic changes.

Keywords: climatic change; ecological change; global change; climate-ecology interactions; surprises, synergisms.

\section{Introduction}

By definition, true global change surprises constitute currently unimagined outcomes from the global change 'experiment' that we are now performing on earth. Formally, what defines a 'surprise'? Probabilities assigned to various outcomes can be objective (e.g. the odds of flipping an unloaded coin) or subjective (e.g. based on prior information that leads an expert to offer a subjective probability that some outcome will occur). 'Risk' is traditionally defined as probability multiplied by the consequence of some known outcome. 'Uncertainty' classically refers to situations where an event or process is factually or hypothetically known, but the probabilities that it will occur are unknown or highly subjective. Surprise, then, is reserved for situations in which even the event or process is not known.

Unfortunately, this formal definition of surprises, while logical, is not very useful. Therefore, following Holling (1986), a workshop (Schneider and Turner, 1995) on global 
change surprises adopted the following as a working definition of surprise: 'Surprise occurs when perceived reality departs qualitatively from expectations'. With this working definition we need not worry whether someone, somewhere, has imagined or modelled some unconventional outcomes, let alone assigned them probabilities.

\section{The climate change example}

Over the past two centuries there has been a documented 25\% increase in carbon dioxide, $150 \%$ increase of methane, the introduction of unnatural chemicals such as chlorofluorocarbons, injection of sulphur oxides, major disturbances to land surfaces, and alterations in precipitation chemistry. Most assessments project global temperatures to rise from about 1 to $4^{\circ} \mathrm{C}$ over the next 100 years if trends in these emissions continue to grow as expected (IPCC, 1996). On the other hand, the typical sustained, globally-averaged rates of surface temperature change from an ice age to an interglacial period is of the order of a degree Celsius per millennium in which globally-averaged temperatures rose typically $5-7^{\circ} \mathrm{C}$, sea level increased by $100 \mathrm{~m}$ or so. The geological record exhibits several paleoclimatic 'surprises' where rapid changes appear to have occurred, at least regionally. Thus, such natural 'surprise scenarios' have led to speculations of analogous, 'greenhouse surprises', (Broecker and Denton,1989).

\section{Traditional 'surprise-free' climate change paradigm: $\mathrm{CO}_{2}$-doubling equilibrium scenarios}

The present paradigm for climatic impact assessment has been to specify scenarios of growth in human population, affluence and associated technologies. These, in turn, produce changes in the land surface or chemical composition of the atmosphere and waters, which, in turn, can modify climate or other environmentally important services essential to food production, pest control, etc. Economic, ecological or decision analytical techniques are used to estimate costs and benefits, distributions of 'winners and losers' or the implications of alternative policy actions. Indeed, Rosenzweig et al. (1993) used just such an approach in which three different $\mathrm{CO}_{2}$-doubled global circulation models (GCM) are applied to evaluate impacts on crop yields, with globally-averaged yields decreasing in the range of $5-10 \%$, if only equilibrium climate change is considered.

Another traditional part of the assessment paradigm is to recognize that there could be mitigating factors, such as the potential effect of the increased concentration of $\mathrm{CO}_{2}$ - this $\mathrm{CO}_{2}$ fertilization effect is believed to make up a substantial fraction of the yield lost. Furthermore, others have argued that farmers would actively adapt to changes, thereby further mitigating potential negative effects (Rosenberg and Scott, 1994). Rosenberg has suggested that studies which ignore this adaptation capacity are implicitly making a 'dumb farmer assumption'. However, we believe some assessments go too far in the opposite direction, implicitly making the equivalent to a 'genius farmer assumption', whereby farmers are assumed to be capable of adapting instantly to all climatic, market and ecological dangers. The degree of adaptability is clearly critical to assessment of ecological or societal impacts of climatic changes.

The assumptions associated with the standard paradigm of global climate change affecting assessment, while recognizing a wide range of uncertainty, are, nonetheless, 
essentially surprise-free. However, we believe that a strategic approach (i.e. one which considers a very wide range of probabilities and consequences) is more appropriate, given the high plausibility of surprises, even if we have but little capacity to anticipate specific details right now. For example, two critical assumptions of the standard assessment paradigm are that climate extremes - drought, floods, hurricanes, etc. - either remain unchanged or will change with the mean change in climate according to unchanged variability distributions. As Mearns and co-workers (1984) have shown, however, changes in the daily temperature variance or the autocorrelation of daily weather extremes can either significantly reduce or dramatically enhance the vulnerability of agriculture, ecosystems or other climate-extreme-sensitive components of the environment to global warming.

Another assumption of the standard assessment paradigm is that 'nature' is either constant or irrelevant in cost-benefit calculations. Yet, should climatic change occur in the middle to upper range of that typically projected, it is highly likely that communities of species now established will be disassembled, and the probability that significant alterations to accustomed patterns of animal pests and weeds seems virtually certain (Root and Schneider, 1993). Some argue that pests, should their patterns be altered, can be simply controlled by pesticides and herbicides. What is not considered in the standard paradigm, but needs to be, is the consideration of surprise scenarios, such as a change in public consciousness over the value of nature that would reject such pesticide/herbicide application as the best choice response to global changes.

Finally, we must confront the following philosophical dilemma: some have argued that even the very suggestion in public discussions of surprises with potentially severe, negative consequences could leverage the popular and political debate over the effects of global warming and possible policy responses either by numbing people into paralysis or scaring them into draconian actions that might exceed those that are efficient given the uncertainty associated with global change. Indeed, those are real risks, but to us it is ethically unacceptable for a small number of experts to keep such information or ideas about surprises within the scientific community, for withholding such information would be substituting our values for that of society at large by denying the political process the knowledge it needs to decide for itself how to react to the potential for surprises.

\section{Interactions and surprises}

It is typically assumed that individual species may respond to climate change by shifting their range limits or abundances. However, most ecological studies concentrate on individual species at the scale of a field plot the size of a tennis court (Kareiva and Andersen, 1988). How to scale up such studies to larger geographical and community levels is not yet based on general theory (Levin, 1992; Ehleringer and Field, 1993; Root and Schneider, 1995). We will discuss later the methods for dealing with the formidable problems of climate/ecology scaling. It can be inferred, however, from a variety of paleoecological studies (e.g. see Root and Schneider, 1993 for several references) that the dispersal rates for specific species of vegetation, mammals, insects, reptiles or birds are all different, yet the interactions among these species may have unique properties (i.e. communities), which suggests that climate change could disrupt current community structure. 
Smith and Tirpak (1988) note that ticks could undergo substantial range changes with $\mathrm{CO}_{2}$ doubling climate change scenarios. This suggests another category of surprises, for which there already has been considerable analysis: human health. Several studies have already suggested that the direct effects of increased heating on cardiovascular disease could lead to increased mortality rates in already warm climates for those who are vulnerable or could also alter disease vectors (Epstein, 1994). However, it is usually noted that adaptations, ranging from simple acclimatization to proper choice of clothing, nutrition, diet, housing, medicine and the like can substantially mitigate high vulnerability to such stress.

Not all surprises need be negative. Climate changes could open new possibilities for growing new kinds of crops. Additionally, on the social side, new technologies may very well yield new positive adaptations, such as a breakthrough in the already rapidly decreasing price of wind energy. As another ecological example, birds able to live further away from the tropics as the globe warms could help control pests within their newly extended ranges. However, not to anticipate the virtual certainty of some negative surprises simply because some could be beneficial would be equivalent to not anticipating unexpected negative threats to personal health or national security and thus forgoing personal insurance or collective defence investments.

\section{Transient effects and climate surprises from non-uniform forcing}

In addition to potential climatic surprises such as a rapid deglaciation of the West Antarctic ice sheet, or shifts in the basic structure of ocean currents, or an increase in the intensity of storms or the length of the hurricane season, there are two other categories of climatic 'surprises' that should be mentioned: (i) transient effects, and (ii) effects from heterogeneous forcing. A time-evolving, transient climate change scenario could very well unfold such that the regional climatic anomalies of the 2010 s would be different in character from those of the 2020s (Schneider, 1994). Under such conditions of change, adapting to recent experience may very well be counter productive for ameliorating future effects.

It has long been known that increasing the quantities of greenhouse gases in the atmosphere causes a heating of the surface-tropospheric system of several watts per square metre (for equivalent $\mathrm{CO}_{2}$ doubling) which, through a number of climatic feedback mechanisms, leads to the enduring $1.5-4.5^{\circ} \mathrm{C}$ equilibrium warming estimate from $\mathrm{CO}_{2}$ doubling (IPCC, 1996). It has also long been known that emissions of sulphur dioxide could lead to further chemical conversions in the atmosphere into sulphate aerosol particles with the potential for cooling the earth by increasing the reflection of sunlight to space either directly or by increasing the reflectivity of clouds. This old debate has recently been rekindled with the suggestion that human industrial production of sulphate aerosols has partially compensated for (i.e. reduced by perhaps one-third) anticipated global warming signals (IPCC, 1996).

El Nino-Southern Oscillation (ENSO) is a prime example of global scale, dynamic interactions known as teleconnections, which are associated with regional oceanic surface temperature anomaly patterns. The relevance of this for global change surprises is the following: there will be a highly heterogeneous global change radiative forcing of the atmosphere through the combination of greenhouse gases, other air pollutants (e.g. near 
surface ozone), cloudiness distribution and sulphate aerosols (to say nothing of biomass burning and land use changes, which both change the surface albedo and put soot and other non-sulphate aerosols in the atmosphere). Not only does this mix of factors imply the need for correction to the globally averaged radiative forcing from the anthropogenic greenhouse effect per se, but could create 'surprise' regional climatic anomalies and related global-scale teleconnections (Schneider, 1994). In fact, recent GCM calculations driven by transient regionally heterogeneous forcings $\left(\mathrm{CO}_{2}\right.$ and sulphate aerosols) produce climatic change patterns much closer to recently observed patterns than models that neglect these effects. This led IPCC (1996) scientists to conclude that a signal of significant climate change has probably been detected in recent observational records and that at least some of this signal can be attributed to human activities.

\section{Ecology/climate scaling issues}

Ecological consequences of natural or anthropogenic global changes could be substantial. There are three traditional research paradigms for studying biotic and abiotic effects of disturbances: (1) scale-up or bottom-up approaches; (2) scale-down or top-down approaches; and (3) scale-up with embedded scale-down components (i.e. parameterizations). We have argued that none of these by themselves will be sufficient for credible ecological assessments. In Root and Schneider (1995) we advocated and presented two examples of existing research efforts (one by an individual investigator, one by an interdisciplinary team) that roughly follow a fourth research paradigm we call strategic cyclical scaling (SCS). SCS involves continuous cycling between refined large- and smallscale studies to achieve two objectives: (1) improved understanding of the behaviour of complex environmental systems, and (2) more reliable forecast capabilities of the ecological consequences of anthropogenic disturbances. The latter is a strategic objective. To reduce uncertainties and improve the likelihood of discovering surprises, we suggest that research institutions and their supporting agencies re-examine current organizational structures to facilitate better the multi-scale, multi-disciplinary, multi-institutional research that the SCS paradigm often requires.

\section{Scale-up}

One standard paradigm is often known as scale-up or bottom-up. This is the idealized 'first principles' approach attempted by most natural science studies. Empirical observations made at small scales are used to determine possible mechanistic associations or 'laws of nature' that are then extrapolated to predict responses at a broad range of scales, particularly larger-scale responses. Some of the most conspicuous features observable at smaller scales, however, may not reveal dominant processes that generate large-scale patterns. Mechanisms creating larger-scale responses can be easily obscured in noisy and/ or unrelated local variations. This often leads to an inability to detect at small scales a coherent pattern of associations (let alone find causal mechanisms) among variables needed for ecological impact assessments at large scales (e.g. see Levin, 1992 and a number of chapters in Ehleringer and Field, 1993).

Consider an ecological example for plants where this extrapolation across scales may not hold. Increasing atmospheric $\mathrm{CO}_{2}$ is likely to enhance photosynthetic activity of plants, because the higher $\mathrm{CO}_{2}$ concentration outside leaves results in a higher partial pressure of 
$\mathrm{CO}_{2}$ inside the leaves. Additionally, water-use efficiency of leaves will probably improve, because the same amount of photosynthate can be produced while stomates remain open for a shorter period of time, thereby reducing transpiration. To quantify such potential effects, agricultural researchers have 'fertilized' isolated food plants in growth chambers with increased $\mathrm{CO}_{2}$, and have found increased yields and water-use efficiency (e.g. Idso and Kimball, 1993).

Before confidently applying a scale-up method, the validity of the forecasting model must be tested at the scale to which it is being applied. For instance, in a tundra ecosystem Oechel and colleagues (1994) observed an initial net uptake of carbon as a result of $\mathrm{CO}_{2}$ fertilization, but found that this initial increase levelled off after a few years. The most important difficulty with the scale-up paradigm occurs in forecasting the behaviour of complex systems. A forecasting model is most credible if it analytically solves a wellvalidated, process-based set of equations that accounts for the interacting phenomena of interest. The classical reductionist philosophy in science indicates that the laws of physics, for example, apply to phenomena at all scales. Thus, in principle, if such laws can be found (usually at small scales), then the solutions of the equations that represent such laws will provide reliable forecasts at all scales. This assumes that all significant phenomena are treated by the laws used in making the forecast. However, this is never possible in practice and, thus, although most forecasting models are predominantly scale-up, they must explicitly or implicitly include some scale-down assumptions.

\section{Scale-down}

The second standard paradigm is often referred to as scale-down or top-down. Observed large-scale patterns are correlated with other such patterns in order to identify possible causal relationships. This approach suffers because the discovered associations may be statistical artefacts that do not, even implicitly, reflect the causal mechanisms that are needed to provide reliable forecasting.

Top-down techniques have long been used to delineate biogeographic limits on largescale biomes. For example, life zone classification assigns biomes (e.g. tundra or tropical moist forest) according to two empirical predictors: temperature and precipitation. Other more complicated top-down empirical formulae have been developed to predict potential vegetation based on combinations of a variety of large-scale predictors (e.g. temperatures or soil moisture). Criticisms have been aimed at the static nature of some such models, which often predict vegetation changes to appear instantaneously with climate changes, neglecting transient dynamics (see references in Root and Schneider, 1995).

\section{Scale-up with embedded scale-down}

To include processes that contribute to transient dynamics, approaches like forest 'gap' models have been developed (see references in Root and Schneider, 1995). These models, which can be driven by climatic transients, include individual species and can address vegetation dynamics. Such models typically assume a random establishment of tree seedlings for various species. Whether these trees grow well or not depends on several different environmental factors such as soil nutrients, shading and solar radiation. Typically, individual tree species are assigned a sigmoid curve for growth in trunk diameter under ideal conditions. 
This approach may appear to be a process-based, scale-up technique, which is reinforced by the small spatial scale typically assumed (e.g. 0.1 hectares). The actual growth rate in the simulation model for each species, however, is usually determined by multiplying the ideal growth rate by a series of growth-modifying functions that attempt to account for the limiting effects of the various environmental factors. For temperature, the growthmodifying function is determined empirically at a large scale by fitting a parabola with a maximum at the value mid-way between the extremes (i.e. temperatures at each species' northern and southern range limits). This embedding of large-scale, regression-based, scale-down empiricism into an ostensibly mechanistic bottom-up modelling approach has been criticized on the grounds that such large-scale curve-fitting exercises are not based on species physiology. Pacala and Hurtt (1993) recommend the use of population-dynamics models with species-specific parameters derived experimentally at large scale, and that include factors such as seed dispersal, so that recruitment is related to the pre-existing population of the plants, not simply a random number generator. Other examples of large scale ecological experiments are reviewed by Carpenter et al. (1995).

\section{Downscaling}

In order to estimate the ecological consequences at small scales of forecast climate change, a researcher must first translate the large-scale climate-change forecast to a region of smaller scale. This means, roughly speaking, translating climate model-generated information at a $200 \times 200 \mathrm{~km}$ GCM grid scale to, perhaps, a $20 \times 20 \mathrm{M}$ field plot - a 10000 -fold interpolation! Such climate models use this coarse resolution because of the practical limitations of modern, and even foreseeable, computer hardware resources. Several methods for downscaling are reviewed in Root and Schneider (1995).

\section{Strategic cyclical scaling}

The deficiencies of the bottom-up, top-down, or scale-up with embedded scale-down paradigms has led us to advocate a fourth, less formalized, paradigm, which we call 'strategic cyclical scaling' (SCS). That is, scale-down and scale-up approaches are cyclically applied in a strategic design that addresses a practical problem: in our context, the ecological consequences of global climatic change. Large-scale associations are used to focus small-scale investigations in order to ensure that tested causal mechanisms are generating the large-scale relationships. Such mechanisms become the systems-scale 'laws' that allow more credible forecasts of the consequences of global change disturbances. SCS, however, is not intended as only a two-step process, but rather a continuous cycling between large- and small-scale studies with each successive investigation building on previous insights from all scales.

\section{Discussion}

The advent or prospect of real surprises or for imaginable events such as those either of low probability or not currently assessable probability, suggests the obvious need for flexibility in managing all systems that depend on environmental factors that are influenced by human activities, not least of which is the ecological interaction with climate change (e.g. Myers, 1995). We believe that impact analysts need to give more attention to 
the emerging climatic impact paradigm of strategic analysis of a spectrum of probabilities and outcomes. Typically, impact assessments, as mentioned earlier, tend to focus on 'best guesses' (e.g. IPCC, $1990 \mathrm{~s}$ best guess of $2-3^{\circ} \mathrm{C}$ warming in the middle of the $21 \mathrm{st}$ century), with uncertainty accounted for often by the selection of two or three equilibrium, $\mathrm{CO}_{2}$-doubled climatic model scenarios, or perhaps even a low, middle and high warming scenario.

We understand, even applaud, such analyses as important early steps in the attempt to integrate physical, biological and social components of environmental impact assessment. However, the alternative paradigm needs to begin to creep in to analytic activities in the form of strategic assessments. By strategic assessment we mean not only analysing central cases of 'best guess' equilibrium changes, but also looking at changes that most affect society and nature: outlier or extreme events. Thus, we must include transients and a wide distribution of outcomes, including some significant, positive and negative surprise scenarios, and should attempt to assign to each of these scenarios some probability or range of probabilities - even though such probabilities will of necessity be highly subjective. The assignment of an intuitive or subjective probability should not be viewed as scientifically pejorative, for most purported objective probabilities, such as the significance level to which a global climate signal can be attributed to human activities, are not really objective as the assignment of formal statistical significance in climate signal detection studies requires (Schneider, 1994) two fundamentally subjective assumptions: (i) what is the long-term (i.e. low frequency) natural climatic (or ecological) variability, and (ii) what have been the time-evolving concentrations of both natural and anthropogenic forcings (such as greenhouse gas build-ups or changes in the solar output or aerosols). Thus, rather than delude ourselves into a false sense of objective analytic security based on some arbitrary (typically 99\%) statistical confidence limit, it is better to recognize that most probabilities assigned to the likelihood of specific environmental consequences in the global change area are based on scientific intuition about the plausibility of underlying assumptions. One hopes that such intuition would be based on the integrated expertise of people from wide-ranging fields familiar with many aspects of the problems and their interconnections (Morgan and Keith, 1995).

A strategic approach in which even relatively low probability or unassignable probability events are analysed for their potential consequences would seem prudent, as is done currently by nearly all defence establishments or in medical practice where relatively low or unknown probability scenarios with significant potential impact outcomes are analysed and sometimes major public or private investments made to hedge against or accelerate the onset of such scenarios.

However, the very predictability of the earth system response will also depend upon the rate at which the system is forced to change. That is, the slower the build-up of greenhouse gases, $\mathrm{SO}_{2}$, land uses or other global change forcings that alter the radiative and chemical balances of the earth-atmosphere system, the closer to an equilibrium approximation each successive estimate will be. That is, a world forced to change slowly will more closely approximate a world of a sequence of equilibrium snapshots. A world forced to change rapidly will require many dynamical interactions to be properly accounted for, and, as such, many surprises can be anticipated.

This discussion of subjective or intuitive judgments to estimate uncertain probabilities for some specified outcomes raises a fundamental question: 'What constitutes a credible 
subjective judgment?'. The typical media debate that puts 'end of the world Cassandras' against 'nothing will go wrong Polyannas' is not the model to choose for credible opinions! It may sell newspapers, but is a distortion of the real spectrum of scientific opinion. It is better to turn to the many national and international assessment teams that integrate broad interests and research disciplines, such as IPCC or the US National Research Council. More recently, decision analytic techniques using sampling surveys to assess subjective probability judgments of experts have been attempted. (Nordhaus, 1994; Morgan and Keith, 1995; Titus and Narayanan, 1996).

\section{What to do: our personal perspectives}

There are obvious first priorities for action: (i) improving flexibility, adaptive management and societal resilience, (ii) focusing research on a range of outcomes (including outliers) and estimates of their probabilities, and (iii) a 'tie-in' strategy emphasizing policies that help to constrain global change forcing and at the same time also provide other benefits (for example, reducing threats to biodiversity, ozone layer reduction, acid deposition, helping with development priorities or investments to eliminate technical inefficiency that both pollutes and reduces economic efficiency).

Nonetheless, many surprises will remain both plausible and unquantified. Schneider and Turner (1995) suggest ways to better anticipate and adapt to global change surprises. Prime among these are more cross-scale, cross-discipline, cross-institution strategic assessments, a 'skeptical welcoming' of unconventional ideas and higher priority on increasing the resilience of society and nature to disturbances as opposed to optimization paradigms based on surprise-free scenarios.

Future adaptation also may be made more viable through some kinds of current actions which Schneider and Thompson, (1985) labelled 'anticipatory adaptations'. These insurance-like activities could include making a dam $3 \mathrm{~m}$ higher than it otherwise would have been made for the purposes of flood insurance, or a bio-reserve larger or a series of reserves interconnected with protected migration corridors. Another form of insurance is a vigorous, international, interdisciplinary, multiscale research programme designed to study the dynamics of the earth system under disturbance, with special focus on uncovering surprise outcomes. If such investments are viewed as strategic 'insurance premiums' at the scale of nations - the minimal level at which most global change forcings will need to be controlled - rather than by individuals and firms, it may be possible to have some rational anticipation that will make adaptation easier over time.

Developing countries will not be in the same financial position as developed countries to make anticipatory environmental investments or the research investments in SCS-like activities, nor do they necessarily have ready access to the most efficient technologies. Dealing with planetary-scale problems will ultimately require a bargaining process that creates acceptable levels of planetary-scale management with enough research support to allow scientists from all nations to be cognizant of the state of the art of earth systems scientific activities.

Working out a way to have nations cede a small degree of national sovereignty, thereby allowing planetary-scale management so that most would benefit through the preservation of our joint environmental commons, may ultimately become the best 'positive surprise' that we could envisage. 


\section{References}

Broecker, W.S. and Denton, G.H. (1989) The role of ocean-atmosphere reorganizations in glacial cycles. Geochim. Cosmochin. Acta 53, 2465-501.

Carpenter, S.R., Chisholm, S.W., Krebs, C.J., Schindler, D.W. and Wright, R.F. (1995) Ecosystem experiments. Science 269, 324-7.

Ehleringer, J.R. and Field, C.B. (eds) (1993) Scaling Physiological Processes: Leaf to Globe. New York: Academic Press.

Epstein, P. R. (1994) Framework for an integrated assessment of health, climate change, and ecosystem vulnerability. Ann. NY Acad. Sci. 740, 423-35.

Holling, C.S. (1986) The resilience of terrestrial ecosystems: local surprise and global change. In Sustainable Development of the Biosphere (W.C. Clark and R.E. Munn, eds) Cambridge: Cambridge University Press.

Idso, S.B. and Kimball, B.A. (1993) Tree growth in carbon dioxide enriched air and its implications for global carbon cycling and maximum levels of atmospheric $\mathrm{CO}_{2}$. Global Biogeochem. Cycle $7,537-55$.

Intergovernmental Panel on Climate Change (1990) J.T. Houghton, G.J. Jenkins and J.J. Ephraum (eds). Climate Change: the IPCC Scientific Assessment. Cambridge: Cambridge University Press.

IPCC (1996) Climate Change 1995 - The Science of Climate Change, the Second Assessment Report of the Intergovernmental Panel on Climate Change: Contribution of Working Group I. (J. J. Houghton, L.G. Meiro Filho, B.A. Callander, N. Harris, A. Kattenberg and K. Maskell, eds). Cambridge: Cambridge University Press.

Kareiva, P. and Andersen, M. (1988) Spatial aspects of species interactions. In Community Ecology: Workshop held at Davis, California, April 1986 (A. Hastings, ed.) pp. 35-50. New York: Springer-Verlag.

Levin, S.A. (1992) The problem of pattern and scale in ecology. Ecology 73, 1943-67.

Mearns, I.O., Katz, R.W. and Schneider, S.H. (1984) Extreme high temperature events: changes in their probabilities and changes in mean temperature. J. Climate Appl. Meterol. 23, 1601-13.

Morgan, M.G. and Keith, D.W. (1995) Subjective judgments by climate experts. Environ. Sci. Technol. 29, 468a-76a.

Myers, N. (1995) Environmental unknowns. Science 269, 358-60.

Nordhaus, W.D. (1994) Expert opinion on climatic change. Am. Sci. 82, 45-52.

Oechel, W.C., Cowles, S., Grulke, N., et al. (1994) Transient nature of $\mathrm{CO}_{2}$ fertilization in Arctic tundra. Nature 371, 500-3.

Pacala, S.W. and Hurtt, G.C. (1993) Terrestrial vegetation and climate change: integrating models and experiments. In Biotic Interactions and Global Change (P. Kareiva, J. Kingsolver and R. Huey, eds) pp. 57-74. Sunderland, MA: Sinauer Associates.

Root, T.L. and Schneider, S.H. (1993) Can large-scale climatic models be linked with multi-scale ecological studies? Conserv. Biol. 7, 256-70.

Root, T. L. and Schneider, S.H. (1995) Ecology and climate: research strategies and implications. Science 269, 331-41.

Rosenberg, N.J. and Scott, M.J. (1994) Implications of policies to prevent climate change for future food security. Global Environ. Change 4, 49-62.

Rosenzweig, C., Parry, M., Fischer, G. and Frohberg, K. (1993) Climate change and world food supply, demand and trade: who benefits, who loses? Global Environ. Change 4, 7-23.

Schneider, S.H. (1994) Detecting climatic change signals: are there any 'fingerprints'? Science 263, 341-7.

Schneider, S.H. and Thompson, S.L. (1985) Future changes in the global atmosphere. In The Global Possible: Resources, Development and the New Century (R. Repetto, ed.) pp. 397-430. New Haven, CT: Yale University Press. 
Schneider, S.H. and Turner, B.L. (1995) Anticipating global change surprise. In Elements of Change 1994 (S.J. Hassol and J. Katzenberger, eds) pp. 130-45. Aspen, Colorado: Aspen Global Change Institute.

Smith, J. and Tirpak, D. (eds) (1988) The Potential Effects of Global Climate Change on the United States: Draft Report to Congress. Vols. 1 and 2. U.S. Environmental Protection Agency, Office of Policy Planning and Evaluation, Office of Research and Development. US Government Printing Office, Washington, DC.

Titus, J.G. and Narayanan, V. (1996) The probability of sea level rise. Clim. Change 33(2), 151-212 